\title{
Efficacy of Solution-Focused Therapy on Depression: A Case Study
}

\author{
Elorm Akpatsa \\ The Graduate School \\ University of Santo Tomas \\ Adrian M. Segovia \\ Department of Psychology \\ Centro Escolar University
}

\begin{abstract}
Objective: This study investigated the efficacy of solution-focused therapy (SFT) as an intervention for major depressive disorder. Method: Therapeutic outcomes of SFT were discovered in this research by employing the case study method. Depression of the research participant was measured using Beck Depression Inventory II (BDI-II) and Hamilton Depression Rating Scale (HDRS). The participant underwent 8 sessions of SFT with at least 45 minutes to one hour per session. Results: Findings of the study indicated that after the intervention, depression level of the participant significantly decreased. Conclusion: It suggests and affirms previous studies that SFT is an effective treatment for depression.
\end{abstract}

Keywords: depression, solution-focused therapy

\section{Introduction}

According to the World Health Organization, depression is the leading mental illness globally (World Health Organization, 2017). The prevalence rate of depression varies world-wide ranges between ten percent (10\%) and fifty-five percent (55\%) (Wright \& Persad, 2007). Data indicates that there are around 4.5 million depressed Filipinos, the highest in the Southeast Asian Region (WHO, 2011). Depression affects an individual's overall functioning, it also includes symptoms of decreased interest, lack of pleasure, changes in sleep pattern and appetite, feelings of worthlessness and significant loss of energy (American Psychiatric Association, 2013). Salk et al. (2016) pointed out that depression symptoms and diagnoses usually begin at the age of 13 and they also discovered the similarity in the chronicity burden between gender which are similar findings in 1980s and 1990s. Depression increases its frequency as early adult life approaches and represents impairments or problems across personal, family, social and educational life of children and adolescents (Kelvin, 2016).

Solution-focused therapy is an offshoot of brief family therapy by Steve de Shazer and Insoo Kim Berg (Connie, 2009). SFT is described as a strengths-based approach which mainly focuses on the individual's resources and its application to the change process (Corcorran and Pillai, 2009) and on helping clients in creating solutions (Gingerich and Eisengart, 2000).SFT as a therapeutic intervention is grounded on the assumption that it is more important to focus on ways on how to solve a client's problem rather than the problem itself (Berg, I.K. and Miller S.D., 1995, and de Shazer et., al. 2007).

Studies shows SFT decreased depression among teenage girls (Javanmiri, L., Kimiaee, S., Hashem Abadi, B.A.G., 2013, Pashapu, D.R., et. al., 2015). Likewise, studies by Gingerichand Peterson (2013), Smock, S.A. et., al. (2008), and Dashtizadeh et., al. (2016) also suggests that SFT has been successful in treating depression among adults. This study was done to contribute on the growing literature about depression and solution-focused therapy.

\section{Case Presentation}

2.1 Identifying Information. FB is a 50-year old separated woman from her husband for 18 years now. She is the second child of four siblings. She has five children and hails from Nasugbu, Batangas but lives in Manila. She completed Bachelor of Science in Accountancy in Centro Escolar University. Currently, FB is employed in Tourism Office (TIEZA) in Makati as a cashier. 
2.2 Presenting Complaints. FB came for treatment as a result of her 18- year history of depressive symptoms. These include low mood, tiredness, sleep difficulty, inability to concentrate, withdrawal from friends and family, increasing tearfulness and feelings of guilt, shame and failure. In addition, FB reported frequently going blank. She complained of feelings of hopelessness and does not know the direction of her life. She also reported that feels lonely most of the time. F. B. ruminates often on the statement that "she has no use in life after five failing grades of the national board exam for civil servants. F. B. considers her issues of broken family, and incapability to find true friends who loved her as a failure as well.

According to F. B. she has entered into love relationship with a man anew but she is not sure how far this relationship will go because of the man's past bad life which is very frightening. She said she is emotionally detached from her children and has little communication with them even though two of her children are staying under the same roof with her. F. B. also often feels that the children ignore her. She is prone to worries about the future of her work, children, and current love affair with her boyfriend. She tends to be uneasy, suspicious of her fellow colleagues at work and socially withdrawn from them. She is currently loosing slowly interest and distaste for her work as cashier because she has not been able to acquired permanent status due to failure to pass the national board exam.

F. B. has trouble falling and staying asleep and complained that she is restless and not at peace in the night. Her biggest stress and anxiety arise when she feels that others are gossiping about her at the workplace and when period of the national examination is drawing near. She wants to be strong again, confident, happy, and be more trustful.

\subsection{Background of the Case}

For about 18 years now since the separation from her husband, F. B. always has been feeling blue about her life situation. She is doubtful about everything and often ask God why me. She has been experiencing mood swings. Sometimes F.B. is happy but in the next moment she feels unhappy. As put in her own words: "I am like a river which is flowing to any direction". She is withdrawn and suspicious of others. F.B. also mentioned that she cannot find herself in any situation and that she sensed that she is totally lost. FB is generally pessimistic and low in energy and she is harboring doubt about her entire life at the moment.

The precipitants of these emotions are first of all when she and her husband got separated. According to her, the husband since then refused to be responsible for the children. The upbringing of the five children was her sole responsibility and it is so stressful because of her low income status. Sometimes, she really cried out her frustration when she could see no help coming from anywhere. Secondly, she felt so sad and trapped when her first boyfriend passed away last two years and she feels guilty because according to her maybe she did not get married to him that's why he died. Thirdly, she was also knocked down by tricycle when she was carrying her fifth pregnancy.

According to her, she felt unconscious for some time and when she woke up she realized she was in the hospital ward. Lastly, last year in December, F.B. took again for the fifth time the Board Examination for civil servants but failed. She felt so disappointed and she ruminated for long time.

At the workplace, FB is often very suspicious about other employees and thinks that they are talking about her and backstabbing her. Because of this, she has begun to withdraw from friends the reason being that she feels insecure at their presence. Sometimes she feels so lonely, hopeless, irritable worried and thinks no one cares about her. Rarely F.B. feels that she wants to die and thinks that she is going crazy. She equally complained of perennial fatigue, stress due to the nature of her work and sexual difficulties because of her myoma. F.B. has recurring thoughts about the separation from her husband and death of her first love and sometimes blame herself for all that has happened.

F. B. has problem concentrating and tends to believe that God is disappointed in her. F.B. says she rarely can do anything right. She mentioned also to have suicidal thoughts but have no plan of carrying it out. Sometimes, she has disorganized thoughts and feeling of dizziness. And she believed these are the hindrances to her peace and happiness. FB also stated that she had dominating parents who spank sometimes and verbally abused her when she goes wrong during her younger age. According to her, the parents were over protective and always wanted their will to be carried out by their children. She described her father as loving, silent and always give the best to the family but that he was alcoholic. With the siblings, F. B. is not closed with them but quickly revealed that there is no conflict between them. 


\section{Case Formulation}

3.1 Precipitants. FB is most anxious and stressed about not passing till now the national board exam of civil servants. She feels that her family has fallen apart. She is worried about not finding true friends and as a result of this she is feeling unloved. FB also is harboring the thought that she has failed in her career. She is not socializing very much now and feels bad about herself and wants to find peace and happiness again and also find probable solutions to her many questions in life.

3.2 Strength and Assets. FB is good at giving helping hands to other people. She senses her worthiness anytime she performs deeds of kindness to other people. She is happy serving the Lord in the Church as a lector. She thinks also that she is better of other people who live and sleep on the street. F.B. cherish taking promenade in the evening after work. She is interested in putting back to track her own life and that of her family.

\section{Case Conceptualization}

\subsection{Identify primary client and significant others:}

4.1.1. Client. FB is an adult female aged 50 years. She is a Filipina from Nasugbu, Batangas province but lives in Manila. Currently, she is working as a cashier on contract in TIEZA. She is living presently with two of her children aged 19 and 17 years. The other three of children aged 26, 25 and 24 are residing with family members in Cainta.

4.1.2 Significant Others. F.B. has a male Filipino partner aged 50 years old who is jobless and staying with the mother. Both parents of F.B. are Filipinos but passed away at aged 45(mother) and (father) 43 respectively. The mother was a homemaker and mostly stayed at home. The father was working but alcoholic. FB has one younger female sibling (40) and a younger male bother (48). Both are currently living in Nasugbu, Batangas Province.

\subsection{Presenting Concerns}

4.2.1. Client Description of Problems. F.B. views herself as a total failure and what precipitated this belief is her inability to pass the National Exam for civil servant. She reported feeling trapped between having to choose to continue to take the National exam or quit her job since she will never been put on regular status. She says she has always love to keep his family together but in recent days she feels her family is broken. She reported the feeling of betrayal of friends and eager to find true friends who will love her. She believes that part of the contributing factor to her failure is that she experienced very dominating parents.

4.2.2. Significant Other/co-worker description of problems. Annie 55 years old believed her co-worker worries a lot these days about the status of her position at the workplace. She said she is aware of the family problems of FB because she has been sharing them with her in the past. Recent days she reported that FB easily get irritated at the least provocation. According to her, FB is almost suspicious of everybody. Annie stated that she is also aware that FB is dating a man through her post on Facebook but she is hesitant to ask her because FB did not share that with her. She often sees FB wiping her face as she weeps often during working hours. She talks very little to coworkers these days reported by Annie.

\subsection{Client Strengths and Diversity.}

4.3.1. Personal. FB is self-disciplined and altruistic individual. She has developed sympathy as cashier and enjoys helping others. She has escaped typical work related troubles and has generally on the average gotten along well with her family. She is creative and imaginative. FB takes interest in pray and reading in the Church as a lector. She enjoys taking a walk along the sidewalk after she closes from work.

4.3.2 Relational/Social. FB's family is averagely close. There is no conflict between FB and her siblings who are living in the Province. These days, she made it habit to visit them every Saturday. Her family value so much care and compassion and her parents have tried very much to send all of them to school. She is excited and takes consolation in her three children who have graduated from college.

4.3.3 Spirituality. FB was raised Catholic and till now she remains so. She values very much serving the Lord as a lector and commentator. She enjoys attending mass and sometimes if there are no mass servers, she acts as a mass server at the altar. She was also a vocalist at her Church. FB believes that God appreciate her services and this brings her happiness. 
4.3.4 Unique Resources. FB has a lot of associates who offer her different views in life. She is kind and sensitive towards others. Although she has doubt about her current boyfriend, he is a strong support for her right now.

4.3.5 Potential Limitations. FB has set certain standard for her that unless she is able to pass the National Board Examination for the civil servants, she will not be completely happy. The low socioeconomic status of FB can also serve as a potential hindrance to her improvement. It is said there is a link between depression and lowincome women which can contribute to increase stress and minimal social support often associated with low socioeconomic status (Bell \& Doucet, 2003). Another potential limitation is that FB is 50 years old and she is in developmental transition period of menopause.

\section{Method}

\subsection{Design}

To explore the efficacy of SFT in depression, the case study design was employed in this study. The participant underwent eight (8) sessions of SFT with at least 45-60 minutes per session. In a review made by Gingerich W. J., and Eisengart, S. (2000) about outcomes of SFT, most of the studies about SFT used 6 to 12 sessions has shown to be effective.SFT sessions were facilitated by a registered psychologist.

\subsection{Outcome Measures}

Efficacy of SFT was evaluated by noting the difference on the pre-and-post intervention scores of the participant on two tests namely: Beck Depression Inventory II (BDI-II) and Hamilton Depression Rating Scale (HDRS). Both tests are widely used in assessing symptoms of depression and has been found out to have good psychometric properties. To measure depressive symptoms after each therapy sessions, Center for Epidemiological Scale for Depression (CES-D) was used.

5.2.1 Beck Depression Inventory-II.BDI-II is a multiple-choice self-report inventory and consists of 21-items. It was created by Aaron T. Beck. The inventory was a 1996 revision developed in response to the American Psychiatric Association's publication of the Diagnostic and Statistical Manual of Mental Disorders, Fourth Edition. Each item is scored on a scale value of 0-3 with standardized cut-offs ranging from "minimal depression" to "severe depression." BDI-II has two subscales: (a) affective and (b) somatic subscale: the affective subscale consists of eight (8) items and thirteen (13) items for the somatic subscale. The internal consistency of BDI-II was satisfactorily high $(\alpha>$ or $=0.84)$, and retest reliability exceeded $r>$ or $=0.75$ in nonclinical samples (Sacco, R. et. al., 2016).

5.2.2 Hamilton Depression Rating Scale. HDRS is an easily administered rating scale for symptoms of depression. The internal consistency of the scale was (Cronbach's alpha $=.80$ ) and has a good convergent validity with depression subdomain of neuropsychiatric inventory (NPI) $r_{\mathrm{rho}}=.85$. (Raimo et. al., 2015).

\section{Results}

\subsection{Initial Impression and Diagnosis}

6.1.1 BDI-II and HDRS Scores. The client scored 33 in Beck Depression Inventory II (BDI-11), this indicates that the client has severe depression; this finding was supported by the client's score in Hamilton Depression Rating Scale (HDRS) of 20, which indicates moderate severity of depression which usually warrants entry for clinical trial.

6.1.2 DSM-5 Diagnosis. Based on clinical assessment, FB is suffering from major depressive disorder with anxious distress.

6.1.3Mental Status. Client is copiously oriented with depressed and anxiety mood (these feeling states indicated only on questioning), ideas of guilt or rumination over past errors or sinful acts and wishes she was dead or possible death to self but no plans of carrying it out, and recurrent disorganized thoughts.

\subsection{Depressive Symptomatology}

FB underwent eight sessions of SFT. In the initial session, FB was assessed using BDI-II and HDRS. In the following sessions, depressive symptoms were assessed using standardized Center for Epidemiological Scale for Depression (CES-D). The symptoms assessed were patterned from DSM-5 category for major depressive disorders. 
The symptoms are as follows: (1) hopelessness, (2) loneliness, (3)irritability, (4) suicidal thought, (5) lack of concentration, (6) guilt, (7) anger, (8) aggression, (9) withdrawal from significant others, (10) fatigue, (11) sleeping problem, and (12) depressed moods. All of the depressive symptoms has shown to have significant improvement all throughout the course of the therapy sessions. For suicidal thoughts, its important to note that while approaching the last sessions of the therapy, there was a marked significant absence of suicidal thoughts in the participant.

\subsection{SFT Interventions: Miracle Question, Scaling Question, and Home Works}

Miracle question, scaling questions, and home works were used in the treatment plan. FB expressed hope and confident of being well again and return to her former way of life. She was optimistic the treatment plan will assist her in achieving this goal. FB find small tasks very helpful. She is feeling very much accepted now by the significant others (family, friends, and co-workers).FB felt well accepted during the counseling session. She felt that her goals were worked at and found the small task very helpful. She reported that her feelings were understood. She was impressed about the session and attested to the fact that we got to the heart of things. In a nutshell, she found the session helpful and was optimistic.

\subsection{Post-intervention Results}

As seen in figure 1, marked improvements in depressive symptoms for both BDI-II and HDRS scores were observed. From an initial 33 to 3 score in Beck Depression Inventory - II and 20 to 5 in Hamilton Depression Rating Scale, it affirms that SFT has been efficient in treating symptoms of depression in FB.

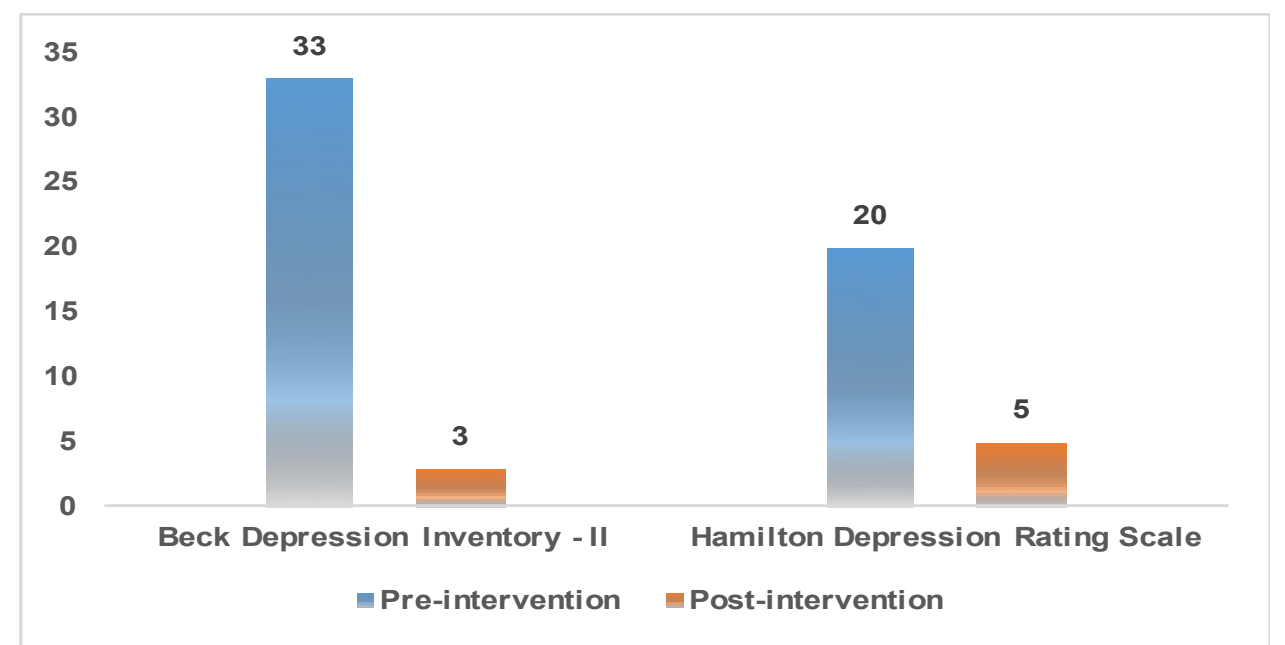

Figure 1. Pre and Post-Intervention Results of BDI-II and HDRS

\section{Discussion}

This study evaluated the efficiency of SFT in treating depressive symptoms on a woman with major depressive disorder. Various studies had been conducted to test the effectivity of SFT on different psychiatric conditions such as substance abuse (Smock S. A. et. al., 2008, and Kim, J.S. et. al., 2016) and alcohol dependence(Spilsbury, G., 2012) - comorbid to depression, adjustment problems (Hosseinpour, N., et. al., 2015). This study further affirms that SFT is an efficient method in reducing symptoms of depression among women.

\section{References}

American Psychiatric Association (2013). Diagnostic and statistical manual of mental disorders, fifth edition. Arlington, VA: American Psychiatric Association

Bell, D. and Doucet, J.B., (2003).Poverty, inequality, and discrimination as sources of depression among U.S. women. Psychology of Women Quarterly. doi: 10.1111/1471-6402.00090

Berg, I.K. and Miller, S.D. (1995). The miracle method: a radically new approach to problem drinking. New York: Norton 2009

Björgvinsson, T. et., al. (2013). Psychometric properties of the CES-D-10 in a psychiatric sample. Assessment. Vol 20, Issue 4, pp. 429 - 436. Sage Journals. doi: 10.1177\%2F1073191113481998 
Connie E. (2009). Overview of solution focused therapy. The art of solution focused therapy. Springer Publishing Company, New York: $1-19$.

Corcorran J., and Pillai, V. (2009). A review of the research on solution-focused therapy. Br J Soc Work 39 (2): 234-242. doi: 10.1093/bjsw/bcm098

Dashtizadeh, N. (2016). Effectiveness of solution-focused brief therapy on reducing symptoms of depression in women. Research Gate. doi: 10.4103/2395-2296.179077

de Shazer, S. et., al. (2007). More than miracles: the state of the art of solution-focused brief therapy. Routledge, New York

Gingerich W. J., and Eisengart, S. (2000). Solution-focused brief therapy: a review of the outcome research. Family Process 39: 477-498. doi:10.1111/j.1545-5300.2000.39408.x

Gingerich W. J., and Peterson L. T. (2013). Effectiveness of solution-focused brief therapy: a systematic qualitative review of controlled outcome studies. Research on Social Work Practice, 23, 266-283.

Hosseinpour, N., et. al. (2015). The efficiency of solution-focused brief therapy on adjustment problems of female students in Amol, Iran. Int School Health. 3(1):e27002. doi: 10.17795/intjsh-27002

Javanmiri, L., Kimiaee S.A., and Hashem Abadi, B.A.G. (2013). The study of solution-focused group counseling in decreasing depression among teenage girls. International Journal of Psychological Studies; Vol. 5, No. 1; 2013 doi: 10.5539/ijps.v5n1p105

Kelvin, R. (2016). Depression in children and young people. Pediatrics and Child Health, Volume 26, Issue 12, December 2016, Pages 540-547. doi: 10.1016/j.paed.2016.08.008

Kim, J.S., et. al. (2016). Solution-focused brief therapy with substance-using individuals: a randomized controlled trial study. Research on Social Work Practice. 1-11. Doi: 10.1177/1049731516650517

Pashapu D.R. et. al. (2015). Effectiveness of solution-focused brief therapy for an adolescent girl with moderate depression. Indian J Psychol Med. 37(1): 87-89 doi: 10.4103/0253-7176.

Raimo, S., Trojano, L., Spitaleri, D. et. al., (2015). Psychometric properties of the Hamilton depression rating scale in multiple sclerosis. Qual Life Res 24: 1973. doi:10.1007/s11136-015-0940-8.

Sacco, R. et. al., (2016). Psychometric properties and validity of Beck depression inventory ii in multiple sclerosis. European Journal of Neurology. doi: 10.1111/ene.12932

Salk, R.H. et. al., (2016). The contemporary face of gender differences and similarities in depression throughout adolescence: development and chronicity. Journal of Affective Disorders, Volume 205, November 2016, Pages 28-35. doi: 10.1016/j.jad.2016.03.071

Smock, S.A. et., al. (2008). Solution-focused group therapy for level 1 substance abusers. Journal of Marital and Family Therapy. Vol. 34, No. 1, 107-120.

Spilsbury, R. (2012). Solution-focused brief therapy for depression and alcohol dependence: a case study. Clinical Case Studies. 11(4) 263-275 doi:10.1177/1534650112450506

World Health Organization (2017). Depression fact sheet. Retrieved from: http://www.who.int/mediacentre/factsheets/fs369/en/

World Health Organization. (2011). Health of adolescents in the Philippines. Retrieved from: http://www.wpro.who.int/topics/adolescent_health/philippines_fs.pdf?ua

Wright, S.L. \&Persad, C., (2007). Distinguishing between depression and dementia in older persons: neuropsychological and neuropathological correlates. Journal of Geriatric Psychiatry and Neurology, 20, 4, 189-198. doi: 10.1177/0891988707308801

\section{Appendix A. Treatment Plan}

\section{Initial Phase of Treatment}

\section{Initial Phase of Counseling Tasks}

1. Develop working counseling relationship with FB. Diversity considerations: Pay attention to pertinent diversity issues (such as gender, race, socioeconomic status, ethnicity, religion etc.

Relationship-building approach/intervention:

a. Building of therapeutic rapport by identifying strengths and weaknesses, resources and guiding language to delineate problems, identify areas of functioning of FB, and breed confidence, faith and optimism.

2. Assess individual, family and broader cultural dynamics. Diversity considerations: pinpoint resources linked to diversity. 
a. Miracle question to obtain behavioral, physiological, emotional and cognitive sketch of solutions and offer motivation to FB

b. Identify exceptions and obtain previous attempted solutions, "what works", pre-session change, assets and strengths.

3. Obtain client perspective on treatment goals and interventions while paying rapt attention to diversity issues.

\section{Goal-making Intervention:}

a. Develop specific, achievable, step-by step goals with client stated in optimistic terms based on miracle questions.

4. Identify needed referrals, crisis issues and other client needs (particularly emotional and physiological needs).

a. Crisis-assessment Intervention(s): Use scaling for safety to curtail crisis issues.

b. Referral(s): refer to religious group organization in the parish (lectors and commentators), connect with community resources, including activities, hobbies, adventures, and movies linked to elements identified in miracle question.

\section{Initial Phase Client Goals}

1. Increase safety, welfare and capability to use resources to reduce depressive and anxiety moods as related to behavior.

Interventions:

a. Motivate FB to use Goldberg mood scales to gauge step-by-step mood reduction.

b. Identify personal, social, relational, family and community resources to provide immediate care for client.

c. Formulate first session tasks to identify what works well right here and now and create hope and optimism.

d. Stabilizing techniques (butterfly hug and deep breathing) to reduce sleep difficulty, fatigue, anger, anxiety etc.

\section{Working Phase of Treatment}

\section{Working Phase Counseling Tasks}

1. Monitor quality of the working alliance. Diversity Considerations: address parent-child relationship and religion (faith).

a. Assessment Intervention: utilize Session Rating Scale; modify working alliance based on client's level of motivation; if intervention does not proof effective, focus on other alternatives.

2. Keep eyes on progress of goals. Diversity considerations: select measures that took into consideration diversity issues.

a. Assessment Intervention: Outcome Rating Scale; weekly scaling questions to measure progress.

\section{Working Phase Client Goals}

1. Increase behaviors derived from "what works" or previous attempted solutions (personal/social/relational dynamic) to lessen depressed mood, hopelessness, emotions, irritation, suicidal thought etc.

\section{Interventions:}

a. Scaling questions to identify specific behavioral tasks each week in view of increasing progress.

b. Provide coping skills/ coping questions to enhance areas of strength and asset application.

2. Increase a set of behaviors identified in miracle question (personal/relational/social) to lessen depressed mood, anxiety, behavioral problems (emotions, irritation, paranoia etc.).

\section{Interventions:}

a. Scaling questions to identify precise behavioral tasks each week in view of increasing progress.

b. Writing compassionate letter to enable client focus on appreciating self and limit self-defeating statements.

3. Increase another set of behaviors identified in miracle question (personal, family/relational, social dynamic) to lessen depressed mood, anxiety, problem behaviors etc.

Interventions:

a. Scaling questions to identify precise behavioral tasks each week in view of increasing progress.

b. Pre-suppositional questions to help client predict solution and construct hope and faith.

4. Long term goal: increase self-esteem to lessen relapse of depressed mood, anxiety, problem behaviors, irritation, emotional problems.

\section{Interventions:}

a. Develop an acceptance of mistakes and failed attempts as another step on the way to success.

b. Tracking self-labeling behaviors and assist client to have a baseline to measure progress in life. III. Closing Phase Counseling Task 
1. Develop post-therapy strategy and maintain achievements. Diversity consideration: involving individual, friends, family and community resources to support client.

Intervention:

a. Adjust miracle question to aid client to imagine future problem and how the client use assets learned in counseling to manage it.

b. Homework (recording every day in a journal negative self-labels to reduce the self-labelling over time to maintain self-esteem).

\section{Closing Phase Client Goals}

1. Increase confidence and hope and put emphasis on new identity related to living the solution (personal, relational, social dynamic) to lessen depressed mood, anxiety, loneliness, rumination, anger, suicidal thoughts, irritation etc.

Interventions:

a. Provide commendations and inspiration to build new identity centered on solution behaviors, choices.

b. Scaling question to reflect on progress made so far and what worked; discuss how to sustain.

2. Increase the use of new coping skills to construct solutions in personal, family, social, interpersonal and occupational situations to lessen depressed mood, anxiety, anger, rumination, sleep pattern, suicidal thought etc.

Interventions:

a. Commendations and inspirations of new skills and capability to adapt them to new situations.

b. Scaling into the future to expect pleasant and unpleasant experiences and how to manage. 